[Aus dem Königl. Institut für Infektionskrankheiten „Robert Koch“ zu Berlin.]

(Direktor: Geh. Obermed.Rat Prof. Dr. Gaffky.)

(Abteilungsvorsteher: Prof. Dr. Lentz.)

\title{
Vergleichende Untersuchungen über den Bacillus der Pseudotuberkulose.
}

Von

Dr. K. Saisawa,

Tokio.

Im Anschluß an die vorhergehende Arbeit möchte ich im folgenden noch kurz über die Ergebnisse meiner Versuche berichten, die ich im Institut für Infektionskrankheiten „Robert Koch" in Berlin auf Anregung ron Hrn. Prof. Dr. Lentz ausgeführt habe. Die von mir festgestellten Befunde dürften vielleicht von einigem Interesse sein; denn seit Preisz vor etwa 18 Jahren vergleichende Untersuchungen über vier von Tieren stammende Pseudotuberkulosebazillen anstellte, ist über derartige Cntersuchungen nur wenig bekannt geworden. Meine Absicht war zunächst, meinen aus Japan mitgebrachten Stamm mit dem von Geheimrat A. Pfeiffer von einem rotzverdächtigen Pferde gezüchteten Stamme zu vergleichen, mit welchem er nach allen Beschreibungen fast ganz übereinstimmt (vgl. vorige Arbeit). Leider konnte ich diesen Bacillus nicht mehr erhalten. Deshalb habe ich zu meinen vergleichenden Untersuchungen 1. einen mir von Geheimrat Prof. R. Pfeiffer aus Breslau übersandten, 2. den von Abel aus Meerschweinchen gezüchteten Stamm aus der Kràlschen Sammlung, 3. den von Dr. Lorey-Hamburg, und 4. den von Prof. Albrecht-Wien gefundenen, vom Menschen stammenden Bacillus herangezogen, über welche letzteren ich in meiner vorstehenden Arbeit kurze Literaturnotizen gebracht habe. Im folgenden berichte ich über meine Resultate. 


\section{Morphologie und knlturelles Verhalten.}

Eine Vergleichung der fünf Bazillenstämme in 24 Stunden alten Kulturen auf schwach alkalischem Agar ergab im hängenden Tropfen und in Fuchsin gefärbten Deckglastrockenpräparaten hinsichtlich ihrer Größe und Gestalt fast völlige ťbereinstimmung; sie waren alle pleomorph; neben kleinen Kokkenformen sah man deutliche Stäbchenformen. Der Pfeiffersche, der Albrechtsche und mein Stamm glichen sich ganz. Der Loreysche Stamm war rundlicher und gröBer, und der Abelsche etwas kleiner als jene. Bei allen war die Diploform vorherrschend. In flüssigen Nährböden, z. B. in Bouillon, hatten sie meist Stäbchenform und bildeten kürzere oder längere Ketten. Sie zeigten keine Eigenbewegung, und die Gramsche Färbung fiel negativ aus. In mit Löfflerschem Methylenblau oder Karbolfuchsinlösung gefärbten Trockenpräparaten färbten sich beide Enden der Bazillen manchmal stärker, während der mittlere Teil sich fast gar nicht färbte (Polfärbung). Besonders gut konnte man das in Ausstrichen aus kranken Geweben sowie von Gewebesaft mittels der Sobernheimschen Polfärbungsmethode nachweisen.

Auch in der Kultur auf künstlichen Nährböden stimmte mein Stamm mit den anderen überein. Eine unwesentliche Abweichung zeigte nur der A belsche Stamm. Er bildete in Bouillon einen starken flockigen Niederschlag, während die obere Schicht der Flüssigkeit fast klar blieb. Die Ursache hierfür ist wahrscheinlich, daB die Bazillen durch die bei diesem Stamm besonders stark vorhandenen schleimigen Stoffwechselprodukte zusammengeklebt sind. Bei längerem Stehen der Bouillonkultur bildete sich eine Kahmhaut, doch kam es nicht zur Stalaktitenbildung wie beim Pestbacillus. Die Kulturen entwickelten einen faden Geruch. Die Indolreaktion - geprüft nach Kitasato und Ehrlich - fiel bei allen Stämmen negativ aus.

Verhalten in Testnährböden: Milch wird nicht koaguliert, Neutralrotagar (Traubenzucker) zeigt keine Gasbildung und verfärbt sich nicht; Lackmusmolke und Milchzuckernutroselösung zeigen nach 1 Tage eine deutlich blaue Farbe, die später noch etwas stärker wird; dagegen zeigen die Bazillen in Traubenzuckernutroselösung deutliche Säurebildung.

Selbst auf stark alkalischem Agar (1 Prozent) wachsen alle Bazillen im Brutofen ziemlich gut. Sie gedeihen sowohl bei 20 bis $37^{\circ}$ gut, als auch bei niederen Temperaturen, z. B. entwickeln sie sich auf gewöhnlichem Agar sogar im Eisschrank (8 bis $10^{\circ} \mathrm{C}$ ) nach 7 Tagen. In verschiedenen kohlehydrathaltigen Nährböden (2 Prozent Pepton-, 1.5 Prozent Kohlehydrat-, 0.5 Prozent Kochsalzlösung, dazu Lackmuslösung) zeigen alle Bakterien dasselbe Verhalten: Dextrose, Maltose, Lärulose, Galaktose, Arabinose, Rhamnose und Mannit werden von ihnen unter Säurebildung 
vergoren, Laktose, Saccharose, Inulin, Dulcit, Sorbit, Inosit, Erythrit, Raffinose und Adonit dagegen nicht angegriffen. Die weiteren Beobachtungen über das Verhalten der Bazillen stimmen im wesentlichen mit dem in meiner ersten Arbeit Mitgeteilten, sowie mit den diesbezügliehen Veröffentlichungen von Albreeht und Lorey überein. SchlieBlich habe ich auch auf 2 und 3 Prozent Kochsalz enthaltendem Agar Kulturen angelegt. Bei 2 Prozent Kochsalzgehalt des Nährbodens zeigten die Bazillen ein kủmmerliches Wachstum, auf dem 3 prozent. Kochsalzagar dagegen waren nach 3 Tagen keine sichtbaren Kolonien entstanden. Die Formen der auf dem ersten Nährboden gewachsenen Bazillen weichen zum Teil erheblich von der Normalform ab. Man sieht überwiegend längliche, fast spindelfōrmige Stäbchen. Manchmal sind sie von auffallender Lānge, oft zu zweien, wie in Teilung begriffen, zusammenhängend. Häufig sieht man auch abnorm groBe, ovale oder mehr runde Formen. Bei der Färbung mit Karbolfuchsin und Löfflerschem Methylenblau färben sich besonders häufig die Enden, manchmal aber auch einige Stellen im Innern tiefer. Die eigentümliche, unförmige Gestalt, wie sie die Involutionsformen von Pestbazillen zeigen, konnte ich aber nicht nachweisen.

\section{Tierversuche.}

In meiner vorigen Arbeit habe ich ausführlich über Versuche mit meinem Pseudotuberkulosebazillenstamm berichtet. Im folgenden will ich in der Hauptsache über die Ergebnisse meiner mit den anderen vier Stämmen an Nagetieren - Kaninchen, Mäusen, Meerschweinchen und Ratten - vorgenommenen Versuche berichten. Besonderes Gewicht habe ich gelegt auf eine genaue vergleichende makroskopische Beobachtung der pathologisch-anatomischen Veränderungen der einzelnen Organe. In folgender Tabelle sind die wichtigsten Veränderungen zusammengestellt.

Tabelle I.

Subkutane Impfung von Meerschweinchen.

\begin{tabular}{c||c|c|c|c}
\hline \hline S t a m m & $\begin{array}{c}\text { Gewicht } \\
\text { des Meer- } \\
\text { schweinch. } \\
\text { in grm }\end{array}$ & $\begin{array}{c}\text { Einverleibte } \\
\text { Dosis leben- } \\
\text { der 24 stünd. } \\
\text { Agarkaltur }\end{array}$ & Ausgang & $\begin{array}{c}\text { Pathologisch-anatomische } \\
\text { Veränderungen }\end{array}$ \\
\hline $\begin{array}{c}\text { Pfeiffer- } \\
\text { scher } \\
\text { Stamm }\end{array}$ & 350 & 2 Ösen & $\begin{array}{c}\text { nach } \\
\text { 12 Tagen } \\
+\end{array}$ & $\begin{array}{c}\text { Impfstelle stark geschwollen, eine } \\
\text { dicke, eitrige, nekrotische Masse ent- } \\
\text { haltend. Netz zusammengerollt, auf } \\
\text { ihm konfluierende Knötchen, Mesen- } \\
\text { terialdrüsen geschwollen. In der } \\
\text { Lunge hier und da kleine Knötchen. } \\
\text { Darmfollikel vergröBert. }\end{array}$ \\
\hline
\end{tabular}


Tabelle I. (Fortsetzung.)

\begin{tabular}{|c|c|c|c|c|}
\hline Sta $\mathrm{m} \mathbf{m}$ & $\begin{array}{c}\text { Gewicht } \\
\text { des Meer- } \\
\text { schweiuch. } \\
\text { in grm }\end{array}$ & $\begin{array}{l}\text { Einverleibte } \\
\text { Dosis leben- } \\
\text { der 24 stünd. } \\
\text { Agarkultur }\end{array}$ & Ausgang & $\begin{array}{c}\text { Pathologisch-anatomische } \\
\text { Verändernngen }\end{array}$ \\
\hline $\begin{array}{l}\text { Abel scher } \\
\text { Stamm }\end{array}$ & 340 & $2 \ddot{O}_{\text {sen }}$ & $\begin{array}{c}\text { nach } \\
14 \text { Tagen } \\
t\end{array}$ & $\begin{array}{l}\text { Impfstelle, Netz und Leber wie vor- } \\
\text { her. Milz stark vergröBert und auf } \\
\text { ihr zahlreiche miliar- bis hirsekorn- } \\
\text { große Knötchen. Lunge entzündlich } \\
\text { und ödematös, auf ihr viele Knöt- } \\
\text { chen. Peribronchialdrüsen auch } \\
\text { vergröBert. }\end{array}$ \\
\hline $\begin{array}{c}\text { Albrecht } \\
\text { scher } \\
\text { Stamm }\end{array}$ & 280 & $"$ & $\begin{array}{c}\text { nach } \\
9 \text { Tagen } \\
\dagger\end{array}$ & $\begin{array}{l}\text { Impfstelle geschwollen, narbiges } \\
\text { Anssehen. Leber und Milz zeigen } \\
\text { unzählbare kleine Knötchen. In der } \\
\text { Lunge keine Knötchen. Darmfollikel } \\
\text { vergröBert. }\end{array}$ \\
\hline $\begin{array}{l}\text { Lorey - } \\
\text { scher } \\
\text { Stamm }\end{array}$ & 295 & $"$ & $\underset{t}{\substack{\text { nach } \\
\text { Tagen }}}$ & $\begin{array}{l}\text { Impfstelle wie bei Nr. 1. Netz } \\
\text { strangartig zusammengeschrumpft. } \\
\text { Leber, Milz, Lunge wie bei Nr. } 1 \text {. } \\
\text { Mesenterial- u. Peribronchialdrüsen } \\
\text { geschwollen, darauf einige sehr } \\
\text { kleine Knötchen. }\end{array}$ \\
\hline $\begin{array}{c}\text { scher } \\
\text { Stamm }\end{array}$ & 320 & $"$ & $\begin{array}{c}\text { nach } \\
12 \text { Tagen } \\
t\end{array}$ & $\begin{array}{l}\text { Impfstelle stark geschwollen und } \\
\text { narbig geschrumpft. Schnittfläche } \\
\text { eitrig-nekrotisch. Leber und Milz } \\
\text { sind von zahlreichen Knötchen durch- } \\
\text { setzt. In der Lunge wenige Knöt- } \\
\text { chen. Mesenterialdrüsen vergröBert. }\end{array}$ \\
\hline
\end{tabular}

Wie man aus Tabelle I sieht, gingen die Meerschweinchen bei subkutaner Impfung unter Abmagerung in 9 bis 14 Tagen zugrunde. Die pathologisch-anatomischen Veränderungen zeigen bei allen Bazillenstämmen fast das gleiche Bild. Die Impfstellen sind stark geschwollen. Bei dem Pfeifferschen, dem Abelschen und dem Loreyschen Stamm sind die eitrigen Veränderungen stärker als bei den anderen Stämmen. Die Bauchorgane, und zwar die Leber und Milz, sind stark entzündlich vergröBert; auf ihnen sind stets weiB-gelbliche Knötshenbildungen vorhanden. In der Lunge bemerkt man mehr oder weniger zahlreich kleine Knötchen, mit Ausnahme des Albrechtschen Falles. In der Niere ist kein Knötchen vorhanden. Das Klatschpräparat eines Knötchens zeigt, daß es meist aus mehr oder weniger stark degenerierten Rundzellen und aus wenigen schmale oder blasige Kerne besitzenden Zellelementen besteht. Hier und da sieht man kleine und große Häufchen ron kokkenförmigen Bazillen. Auch konnte ich aus den Knötchen und dem Blut, sowie aus der Pleuraund Peritonealflùssigkeit die Bazillen wieder züchten. 
Intraperitoneale Impfung von Meerschweinchen.

Ich habe von jedem Stamm je 1 Öse 24 stündiger lebender Agarbultur in die Bauchhöhle der Meerschweinchen (Körpergewicht 280 bis $350 \mathrm{grm}$ ) eingespritzt. Die mit dem Pfeifferschen und dem Albrechtschen Stamm geimpften Meerschweinchen starben nach 3 Tagen; das mit dem Abelschen Stamm infizierte nach 4 Tagen und das mit dem Lorey schen Stamm geimpfte nach 5 Tagen. Die Sektionsbefunde ergaben in allen Fällen fast gleiche anatomische Veränderungen. Die Bauchhöhle enthielt mehr oder weniger reichlich rötlich-gelbes Exsudat. Die Leber und Milz waren vergrōßert. Die Nieren waren ebenfalls entzūndlich hyperämisch. Das Netz war bei allen Tieren aufgerollt und strangartig geschrumpft. Es war mit kleineren und größeren gelblich-weißen Knötchen durchsetzt. Darmserosa, Harnleiter und die anhāngenden Organe waren blutreich, ödematös. Die Mesenterialdrüsen waren manchmal vergrōßert. In der Pleurahöhle sowie im Perikard hatte sich etwas Flüssigkeit angesammelt. Die Lungen waren hyperämisch. Es zeigten sich also in erster Linie Exsudate in den serösen Höhlen und starke entzündliche Erscheinungen in den Bauchorganen. Knötchenbildung fand ich indessen nur auf dem Netze.

Tabelle II.

Intraperitoneale Impfung von Kaninchen.

\begin{tabular}{|c|c|c|c|}
\hline $\mathrm{St} \mathbf{a} \mathbf{m}$ & $\begin{array}{l}\text { Gewicht des } \\
\text { Kaninchens } \\
\text { in grm }\end{array}$ & $\begin{array}{c}\text { Verimpfte } \\
\text { Dosis lebend. } \\
\text { Agarkultur }\end{array}$ & A us $g$ ang \\
\hline Pfeifferscher Stamm & 1800 & 3 Ösen & nach 14 Tagen $\dagger$ \\
\hline Abelscber Stamm & 2050 & $"$ & $" \quad 20$ \\
\hline Albrechtscher Stamm & 2100 & $"$ & , 11 \\
\hline Loreyscher Stamm & 1900 & $\eta$ & , 13 \\
\hline Seisawascher Stamm & 2000 & , & " 10 \\
\hline
\end{tabular}

Nach intraperitonealer Infektion starben Kaninchen also binnen 10 bis 20 Tagen. Die anatomischen Veränderungen waren fast die gleichen, wie ich sie bei meinem Fall natürlicher Infektion beim Menschen und bei den Meerschweinchen nach subkutaner Einspritzung gesehen hatte. Die Bauchhöhle enthielt ein gelbliches Exsudat, und das Netz war nach oben strangartig zusammengerollt. Auf der Leber, Milz und Lunge waren zahlreiche und sehr charakteristische Knötchen. Bei den nach längerer Zeit gestorbenen Kaninchen - Pfeifferscher und Abelscher Stamm war die Milz bedeutend vergrößert. Bei dem mit dem Abelschen Stamm 
infizierten Tiere bemerkte ich auf ihr erbsengroße Knoten mit einem dick-eitrigen Inhalt. Auch in der Lunge fanden sich verhāltnismäBig große Knötchen. Bemerkenswert war ferner die Knötchenbildung im Knochenmark der Rippen und des Sternums. Schon durch die Knochenwand hindurch konnte ich hier eine gröBere Anzahl gelblich-weißer Fleckchen erkennen. Bei den mit dem Pfeifferschen, Abelschen und Albrechtschen Stamme behandelten Tieren konnte ich ferner Hyperplasie der Follikel im unteren Teil des Ileums und in der Ileocöcalgegend konstatieren; doch war keine Geschwürsbildung eingetreten. Auf der Niere hatten sich bei den mit dem Abelschen und Albrechtschen Stamm infizierten Kaninchen einige miliare Knötchen gebildet. Die Mesenterialund Peribronchialdrüsen waren vergröbert.

\section{Versuche an weiBen Mäusen.}

Nach subkutaner Impfung mit 1/2 Öse lebender Bazillen starben die Mäuse in 8 bis 11 Tagen. Wenngleich auch die Befunde bei der Sektion nicht so auffallend waren wie bei den Meerschweinchen und Kaninchen, so waren doch Leber und Milz deutlich vergrößert, und ich bemerkte auf ihnen mehrere kleine, oberflächlich sitzende Knötchen. Die Lunge war hyperämisch, doch konnte ich auf ihr keine Knötchen entdecken.

Nach intraperitonealer Einspritzung von $1 / 2$ Ose lebender Kultur starben die Mäuse binnen 2 bis 3 Tagen. Es fanden sich Exsudat und fibrinöse Massen in der Bauchhöhle sowie eine entzündliche Schwellung der Bauchorgane, sonst aber keine bemerkenswerten Veränderungen.

\section{Versuche an Ratten.}

Nach intraperitonealer Einspritzung von $1^{1 / 2}$ Ose lebender Bazillen gingen die Ratten in 4 bis 8 Tagen zugrunde. Das Netz schrumpfte zusammen wie bei den Meerschweinchen und war mit einer käsigen eitrigen Masse bedeckt. Die Leber und noch mehr die Milz waren ververgröBert. Weiter zeigte sich keine bemerkenswerte Veränderung. Bei subkutanen Impfungen (einverleibte Dosis 2 Osen) blieben alle Tiere am Leben; sie wurden dann nach 20 Tagen getötet und seziert, es fanden sich jedoch keine pathologischen Veränderungen bei ihnen.

Aus obigen Tierexperimenten geht hervor, daB die Pathogenität aller untersuchten Bakterienstāmme gegenüber Nagetieren, besonders Meerschweinchen, Kaninchen und Mäusen annähernd gleich ist. Besonders. 
ist die reichliche Knötchenbildung in den Bauchorganen, in der Leber und Milz auffallend. Bei den mit dem Pfeifferschen und Abelschen Stamm infizierten Tieren war die weit vorgeschrittene eitrige Einschmelzung der Knötchen bemerkenswert. Die Ratten zeigten bei meinen Versuchen in den Bauchorganen keine deutliche Knötchenbildung, während in Gegensatz hierzu Albrecht auch bei ihnen Knötchenbildung festgestellt haben will.

\section{Verhalten der Bakterien gegen Immunserum.}

Um die Immunitätsreaktionen an den Bazillen zu prüfen, habe ich Kaninchen mit den von mir untersuchten Stämmen auf intravenösem Wege immunisiert. Dazu wurden von 24 stündigen Agarkulturen Kochsalzaufschwemmungen hergestelit und 1 Stunde lang auf $58^{\circ} \mathrm{C}$ erwärmt, so daB, wie die angestellten Kontrollen ergaben, die Bazillen sicher abgetötet waren. Als Anfangsdosis verimpfte ich 1/4 Ose Agarkultur; in allmählich ansteigender Dosis gab ich den Tieren im ganzen mit acht Einspritzungen 10 Ösen Kultur. Die abgetöteten Bazillen wirkten auf Kaninchen stark giftig. Oft starben schon mehrfach vorbehandelte Tiere nach einer Einspritzung von 2 bis 3 Osen plötzlich oder gingen unter starker Abmagerung ein. Ich habe die Einspritzungen an zwei Serien von Kaninchen gemacht, und auf diese Weise von jedem Stamm 2 Sera gewonnen. Da diese Sera bei der Auswertung fast gleiche Resultate lieferten, gebe ich im folgenden nur die Resultate von je einem Serum wieder.

\section{Agglutinationsreaktion.}

Die Agglutinationsversuche habe ich, wie die Tabellen IIIa bis IIIe zeigen, so ausgeführt, daß ich alle fünf Stämme mit allen Seris kreuzweis austitrierte. Dazu füllte ich zunächst in die Röhrchen $0.5 \mathrm{~cm}$ fallender Serumverdünnungen und gab dazu in jedes Röhrchen $0.5 \mathrm{~cm}$ einer Bazillenaufschwemmung von 1 Ose Kultur in $1 / 2 \mathrm{~cm}$ Kochsalzlösung. Dadurch wurde das in den Röhrchen enthaltene Serum auf die Hälfte der ursprünglich vorhandenen Konzentration verdünnt, und jedes Röhrchen enthielt nun in $1 \mathrm{com}$ Serumverdünnung 1 Ose Bazillenkultur. Ich war zu diesem Verfahren dadurch gezwungen, daB die Kulturen sich schlecht rerrieben und krümelten; die dabei ertstehenden Bröckel sanken bei kurzem Stehen der Aufschwemmungen zu Boden, nur bei dem A belschen Stamm muBte die Aufschwemmung kurze Zeit zentrifugiert werden. Die Beurteilung der Reaktion geschah, nachdem die Agglutinationsproben 24 Stunden bei Zimmertemperatur gestanden hatten, makroskopisch. 


\section{Tabelle III.}

a) Agglutinationsversuch mit Pfeifferschem Serum.

\begin{tabular}{|c|c|c|c|c|c|c|c|c|c|c|c|c|}
\hline \multicolumn{4}{|c|}{ St a m m } & : & 9 & $\frac{8}{\therefore}$ & 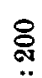 & 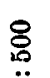 & $\begin{array}{l}8 \\
\end{array}$ & 용 & 号 & 0 \\
\hline Pfeiffer & & 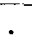 & . & + & + & + & + & + & + & - & - & - \\
\hline Saisswa & . . & . &. & + & + & \pm & - & - & - & - & - & - \\
\hline Abel & . . & . & . & + & + & + & - & $\ldots$ & 一 & - & - & - \\
\hline Albrecht & . . & . & . & + & + & + & - & - & - & - & - & - \\
\hline Lorey . & . . & . & . & + & + & + & \pm & - & - & - & - & - \\
\hline
\end{tabular}

b) Agglutinationsversuch mit Saisawa schem Serum.

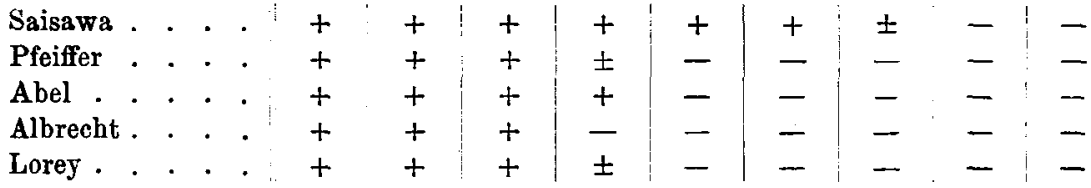

c) Agglutinationsversuch mit Abelschem Serum.

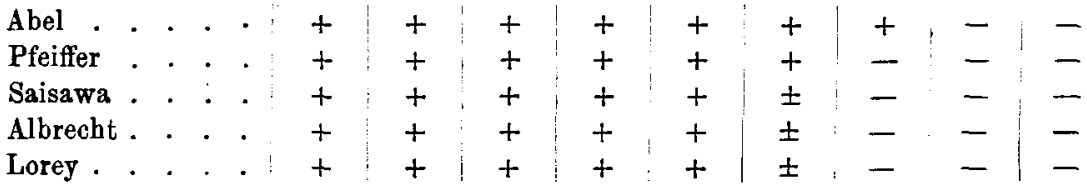

d) Agglutinationsversuch mit Albrecht schem Serun.

\begin{tabular}{lllll|l|ll|l|l|l|ll} 
Albrecht. & $\cdot$ & $\cdot$ & $\cdot$ & + & + & + & + & + & + & \pm & - & - \\
Pfeiffer . & $\cdot$ & $\cdot$ & $\cdot$ & + & + & + & \pm & - & - & - & - & - \\
Saisawa.. & $\cdot$ & $\cdot$ & $\cdot$ & + & + & + & \pm & - & - & - & - & - \\
Abel . & $\cdot$ & $\cdot$ & $\cdot$ & + & + & + & - & - & - & - & - & - \\
Lorey. & $\cdot$ & $\cdot$ & $\cdot$ & + & + & + & - & - & - & - & - & -
\end{tabular}

e) Agglutinationsversuch mit Loreyschem Serum.

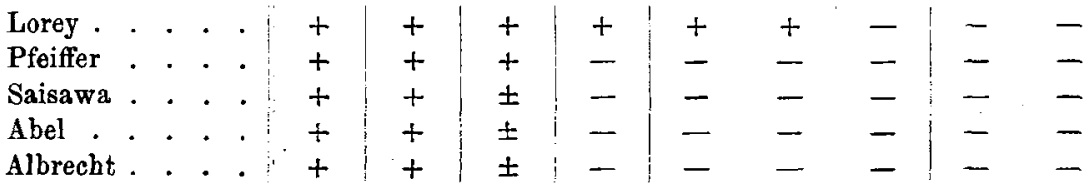

Aus den Tabellen IIIa bis III e geht hervor, daB der Agglutinationstiter der Immunsera gegenüber dem homologen Stamme trotz vorsichtigen Verfahrens bei der Immunisierung und trotz Darreichung von ziemlich großen Mengen Bazillen verhältnismäBig niedrig ist. So betrãgt der 
Endtiter bei dem Pfeifferschen und Loreyschen Serum 1:1000, bei dem $A$ belschen Serum erreicht er 1:2000, und bei den anderen Seris (Saisawa und Albrecht) kaum 1:2000. Die vier Sera (Pfeiffer, Saisawa, Lorey, Albrecht) agglutinieren die heterologen Stämme bedeutend schwächer als die homologen Stämme, so daB die Reaktion erst in einer etwa 10. bis 20 fachen Serumkonzentration eintritt. Dagegen wirkt das Abelsche Serum gegen alle Stämme fast gleich stark, wenn auch gegen die heterologen nicht ganz bis zu seinem Endtiter. Den Versuch habe ich ferner so wiederholt, daB ich die Röhrchen etwa 20 Stunden lang im Brutofen bei $37^{\circ} \mathrm{C}$ oder 3 Stunden lang bei $50^{\circ} \mathrm{C}$ stehen lieb. Bei diesen beiden Verfahren fielen die Reaktionen etwas deutlicher und stärker aus, doch trat kein Steigen des Titers ein. Dieser Ausfall der Agglutinationsprüfung ist sehr auffallend; er deutet auf eine groBe Verschiedenheit im Rezeptorenapparat dieser doch sicher sehr nahe verwandten, wenn nicht identischen Bakterienstämme hin. Die meisten gemeinsamen Rezeptoren scheint der Abelsche Stamm zu besitzen, während die anderen Stämme deren nur sehr wenige aufweisen. Notwendigerweise drängt sich hier die Frage auf, ob es sich bei den fünf untersuchten Stämmen tatsächlich nur um rerwandte, nicht identische Stämme handelt, oder ob bei den Bazillen der Pseudotuberkulose der Nager der Rezeptorenapparat bei den verschiedenen Stämmen so verschieden ausgebildet ist, daB die Agglutinationsreaktion für ihre Identifizierung ungeeignet ist. Um diese Fragen zu prüfen, habe ich noch folgende-Reihe weiterer Untersuchungen angeschlossen. Die Prüfung der Agglutinabilität der fünf Stāmme gegenüber verschiedenen normalen menschlichen und tierischen Seris - Kaninchen, Meerschweinchen, Pferd, Hammel, Affe! - ergab keine Anhaltspunkte, da selbst in stärkeren Serumkonzentrationen (z. B. 1:10) bei keinem der Stämme Agglutination auftrat. Das Gleiche gilt von dem Verhalten der Bazillen gegenüber Pestserum aus dem Pasteursehen Institut. Nur in starker Serumkonzentration $(1: 10)$ bemerkte ich gelegentlich eine schwache, undeutliche Reaktion. Diese Beobachtung steht in einem Gegensatz zu der von Zlatogoroff, der bei den von ihm geprüften zwei Stämmen noch in Serumverdünnungen von 1:200 bis 1:500d. h. fast bis zu demselben Titer wie bei Pestbazillen - deutliche positive Reaktionen gesehen haben will.

Wenn auch meine Agglatinationsversuche ein spezifisch verschiedenes Verhalten der Bazillen der Pseudotuberkulose einerseits und der Pestbazillen andererseits erwiesen haben, so zeigen die beiden Bakterienarten doch andererseits in ihrer Form, in ihrem kulturellen Verhalten und bezüglich ihrer Pathogenität für Nagetiere eine bemerkenswerte Åhnlichkeit, worauf auch Galli-Vallerio und Zlatogoroff hingewiesen haben. Es 
wäre deshalb eigentlich logischer, diese Bazillen mit dem Namen Pseudopestbazillen zu belegen, zumal auch die durch sie und den Pestbacillus herrorgerufenen pathologisch-anatomischen Veränderungen weitgehende Analogien aufweisen.

\section{Präzipitationsreaktion.}

Ferner prüfte ich das Verhalten von Kulturfiltraten gegen spezifisches Serum im Präzipitationsversuch. Als Antigen habe ich das Berkefeldfiltrat einer 2 wöchigen Bouillonkultur, sowie das Zentrifugat einer gleichen Kultur verwandt. Trotz genauer Beobachtung konnte ich bei keinem Serum eine Ausflockung nachweisen.

\section{Komplementbindungsversuch.}

Den Versuch habe ich in üblicher Weise unter Beobachtung aller üblichen Kontrollen ausgeführt. Als Antigen habe ich in folgender Weise hergestellten wässerigen Bazillenextrakt benutzt. Ich schwemmte eine 24 stündige Agarkultur in $\mathrm{Kollescher}$ Schale mit $5 \mathrm{ccm}$ destillierten Wassers auf und schüttelte die Bazillenemulsion bei Zimmertemperatur 48 Stunden lang im Schüttelapparat; alsdann wurde sie zentrifugiert und abpipettiert. Von diesem Extrakt verwendete ich bei dem Versuche $0.05 \mathrm{~cm}$. Wie aus folgender Tabelle $\mathrm{zu}$ ersehen ist, konnte ich im A belschen Serum komplementbindende Substanzen nachweisen. Die Extrakte aus allen fünf Stämmen verhielten sich diesem Serum gegenüber fast gleich; nur der Extrakt des homologen (A belschen) Stammes ergab eine etwas stärkere Reaktion als die übrigen.

\section{Tabelle IV.}

Versuch mit Abelschem Serum.

\begin{tabular}{|c|c|c|c|c|c|}
\hline Serum & $\begin{array}{c}\text { Extrakt } \\
\text { Abel }\end{array}$ & $\begin{array}{l}\text { Extrakt } \\
\text { Pfeiffer }\end{array}$ & $\begin{array}{c}\text { Extrakt } \\
\text { Saisawa }\end{array}$ & $\begin{array}{c}\text { Extrakt } \\
\text { Albrecht }\end{array}$ & $\begin{array}{l}\text { Extrakt } \\
\text { Lorey }\end{array}$ \\
\hline $0 \cdot 1$ & $\mathbf{H}$ & $\mathbf{H}$ & $\mathrm{H}$ & $\mathbf{H}$ & $\mathrm{H}$ \\
\hline $0 \cdot 05$ & $\mathbf{H}$ & $\mathbf{H}$ & $\mathbf{H}$ & $\mathbf{H}$ & H \\
\hline 0.02 & $\mathrm{H}$ & $\mathrm{SH}$ & SH & SH & SH \\
\hline 0.01 & SH & KK & GK & $\mathbf{K K}$ & GH \\
\hline 0.005 & GK & FKL & FKL & FKL & FKL \\
\hline 0.002 & FKL & $\mathrm{KI}$ & $\mathrm{KL}$ & KL & $\mathbf{K L}$ \\
\hline 0.001 & KI & KL & $\mathrm{KL}$ & $\mathrm{KL}$ & $\mathbf{K L}$ \\
\hline $\begin{array}{c}\text { normales } \\
\text { Kaninchen- } \\
\text { Serum } 0 \cdot 2\end{array}$ & $\mathrm{KL}$ & KL & $\mathrm{KL}$ & $\mathrm{KL}$ & $\mathbf{K L}$ \\
\hline
\end{tabular}

$\mathrm{H}=$ komplette Hemmung. $\mathrm{SH}=$ starke Hemmung.

$\mathrm{GH}=$ Hemmung mit großer Kuppe. $\quad \mathrm{KK}=$ Hemmung mit kleiner Kuppe. FKL $=$ fast komplette Lösung. $\quad \mathrm{KL}=$ komplette Lösung 
Das Pfeiffersche und Albrechtsche Serum gaben nur mit den Extrakten aus ihren homologen Stämmen geringe Wirkung, aber bewirkten selbst in Dosen von $0.1^{\mathrm{cm}}$ keine komplette Hemmung, sondern nur Hemmung mit grober Kuppe. Auch mit den anderen Extrakten ergaben sie denselben Hemmungsgrad. Bei dem Saisawaschen Serum trat die komplette Hemmung mit dem eigenen Extrakt bei Verwendung von $0.05 \mathrm{ccm}$ Serum ein; aber mit anderen Extrakten erst bei $0.1 \mathrm{~cm}$. Bei dem Loreyschen Serum zeigte sich bei $0.05^{\mathrm{cem}}$ mit dem Extrakt des homologen Stammes starke Hemmung; bei Verwendung des Pfeifferschen und Saisawaschen Extraktes trat in $0.1 \mathrm{~cm}$ Serum starke Hemmung ein; bei den anderen beiden Extrakten Hemmung mit großer Kuppe. Die Reaktion war also bei den anderen vier Seris nur schwach und unspezifisch.

4. Schutzwirkung des Immunserums bei simultaner Bakterieninfektion.

Um festzustellen, ob durch Anwendung des obigen Immunserums infizierte Tiere gerettet werden können, und gleichzeitig seine Einwirkung auf einverleibte Bazillen zu prüfen, habe ich Bazillen und Immunserum simultan in die Leibeshöhle von Meerschweinchen eingespritzt. Ich habe nach 1 Stunde und nach 24 Stunden die Leibesflüssigkeit mikroskopisch untersucht und die Tiere weiter beobachtet. Die Resultate dieses Versuches sind in den folgenden Tabellen $\mathrm{Va}$ und $\mathrm{Vb}$ zusammengestellt.

Wie man aus diesen beiden Tabellen ersieht, können Kaninchenimmunsera selbst in starker Konzentration $(1: 10)$ bei simultaner peritonealer Einspritzung von Bazillen des homologen Stammes oder heterologer Stämme das Leben der Meerschweinchen nicht retten. Die Resultate stimmen mit den Ergebnissen Loreys überein. Es trat in der peritonealen Hõhle nach 1 Stunde unvollkommene Bakteriolyse ein, ebenso Phagozytose (bei Serumverdünnungen von 1:10 und 1:20 ziemlich deutlich). Nach 24 Stunden sah ich deutliche Granulabildung, massenhafte Leukozyten und Phagozytose, daneben aber noch freie Bakterien. Die Tiere gingen in 3 bis 4 Tagen zugrunde. Immerhin war eine geringe Verzögerung des tödlichen Ausganges bei den mit höheren Dosen des Immunserums behandelten Tieren und zwar bei Verwendung des homologen Stammes regelmäBig, bei Verwendung heterologer Stämme in einem Teil der Fälle bemerkbar; gleichwohl ist diese nicht so groB, daß man von einer ausgesprochenen, schützenden Wirkung des Immunserums sprechen könnte. Dabei ist aber andererseits in Betracht zu ziehen, daB es sich um verhältnismäBig geringwertige Sera handelte. 


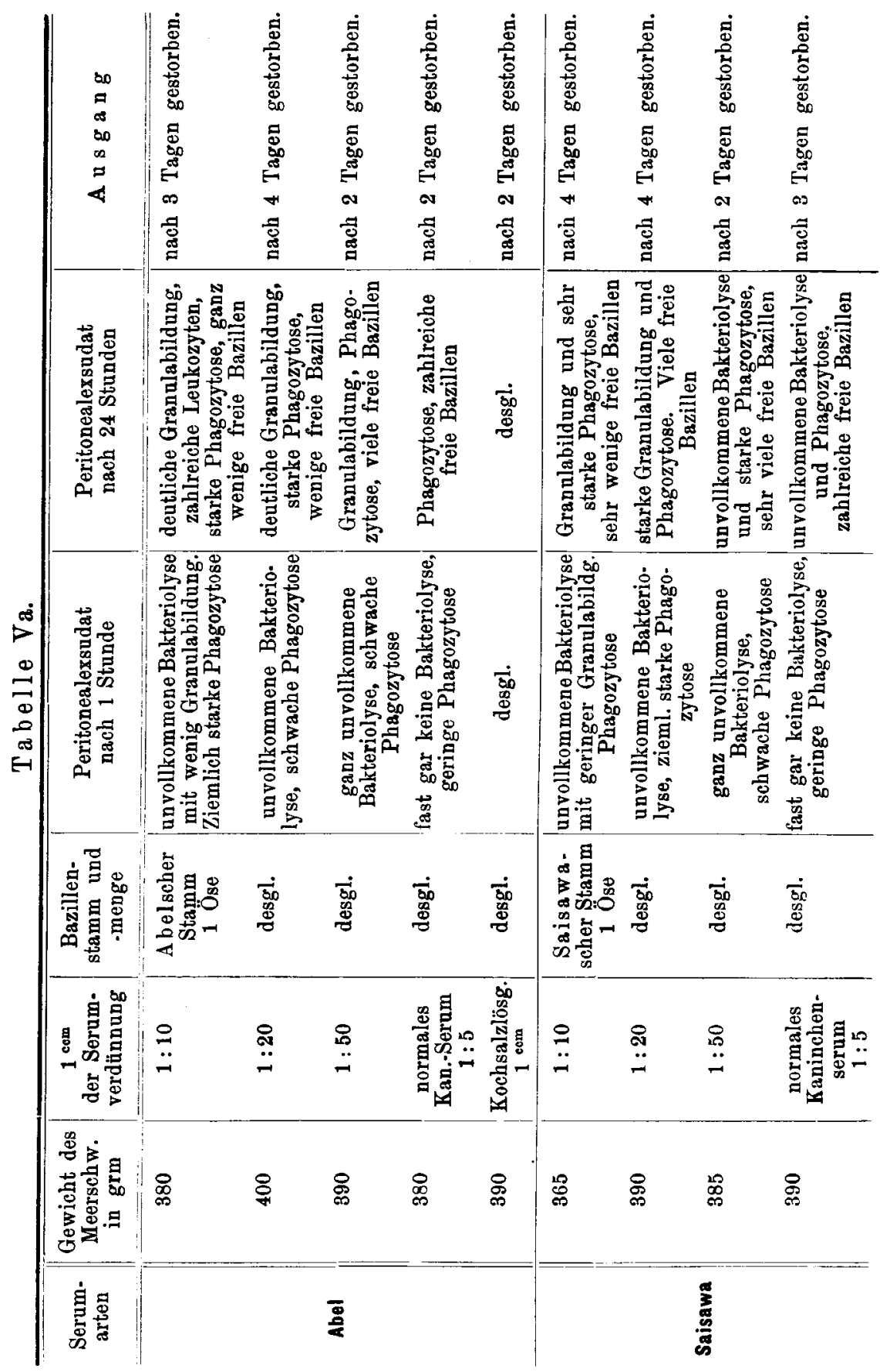


Uber den Baciluds der Pseddotuberrolose.

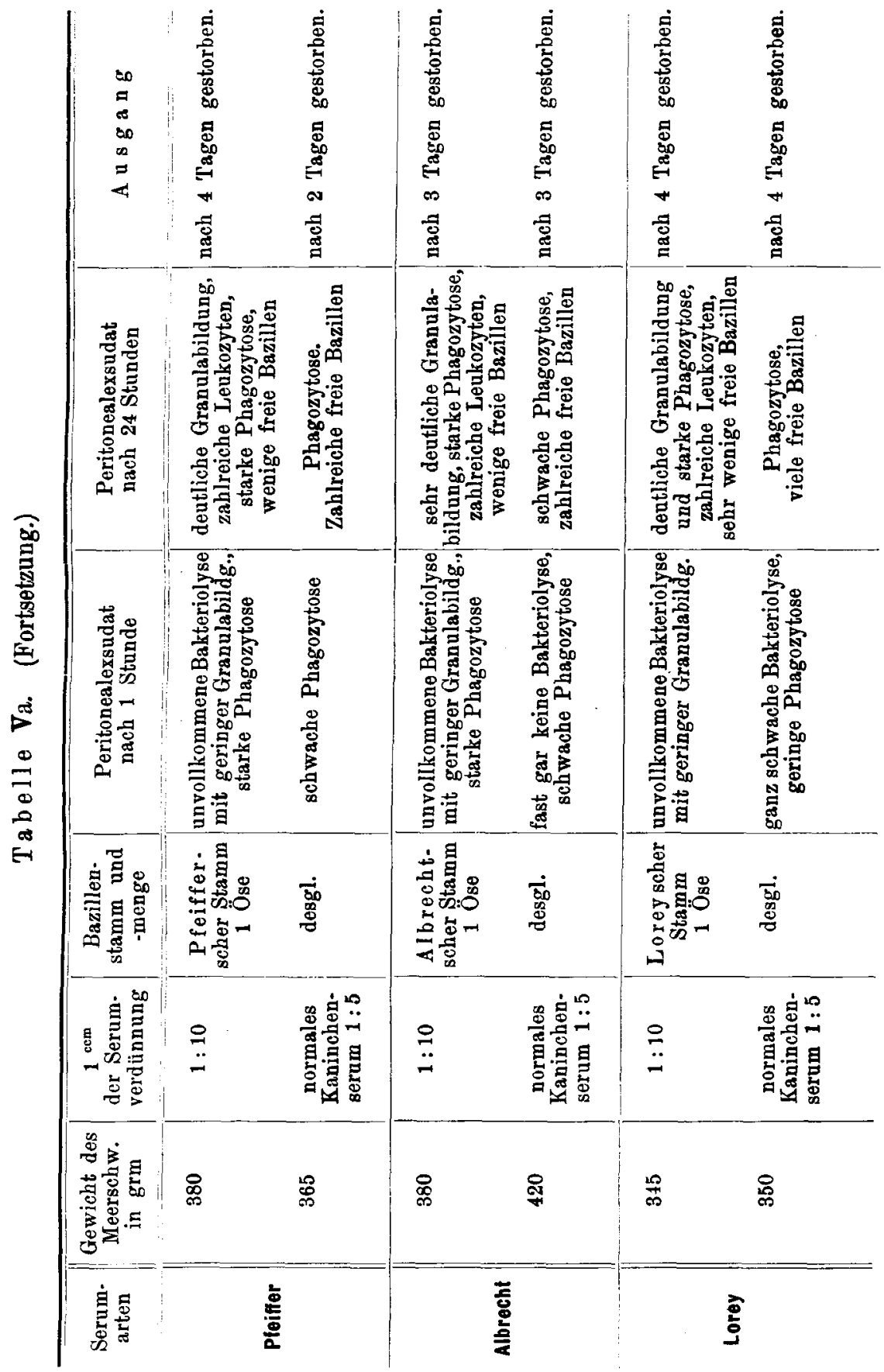




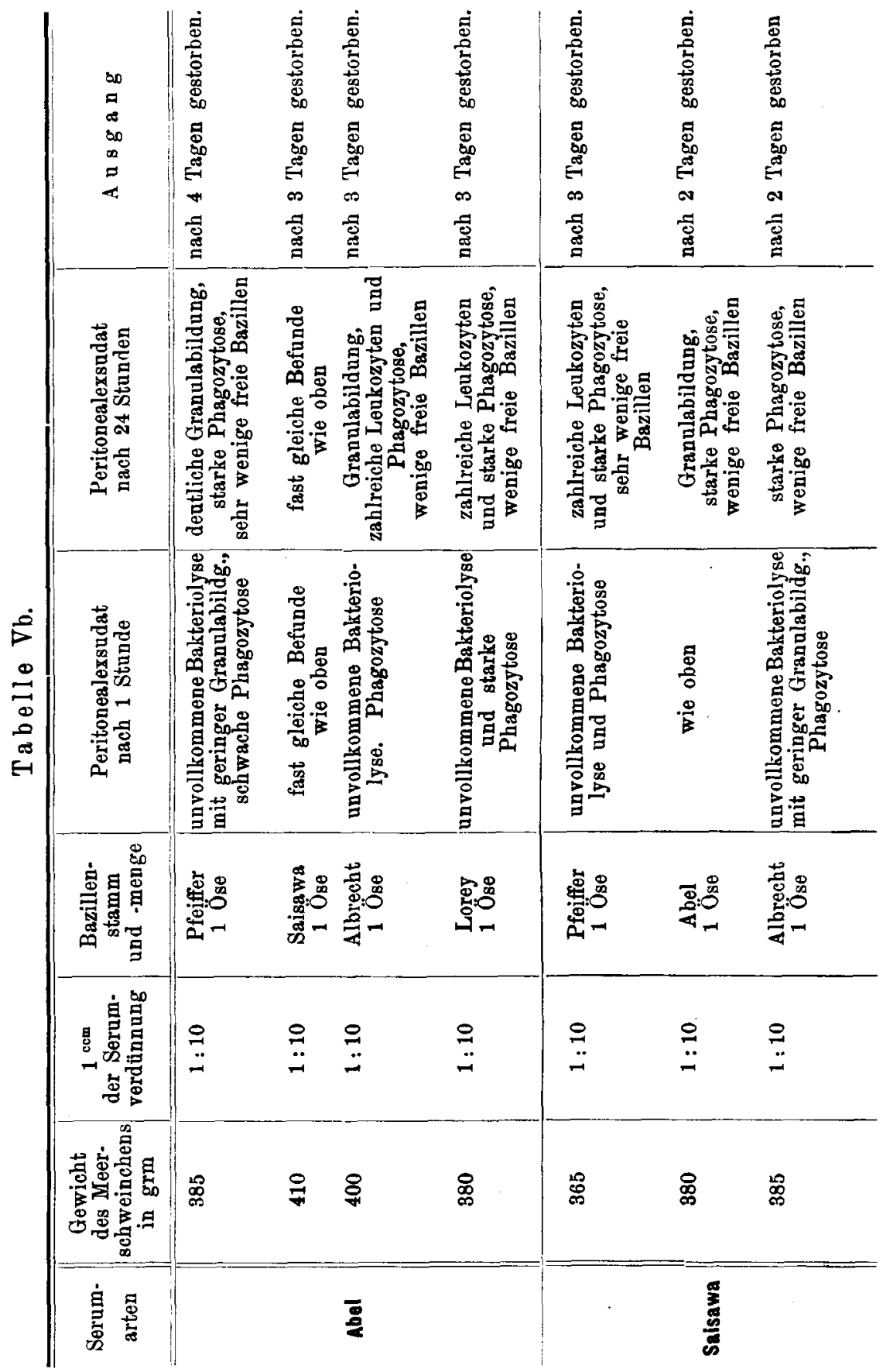




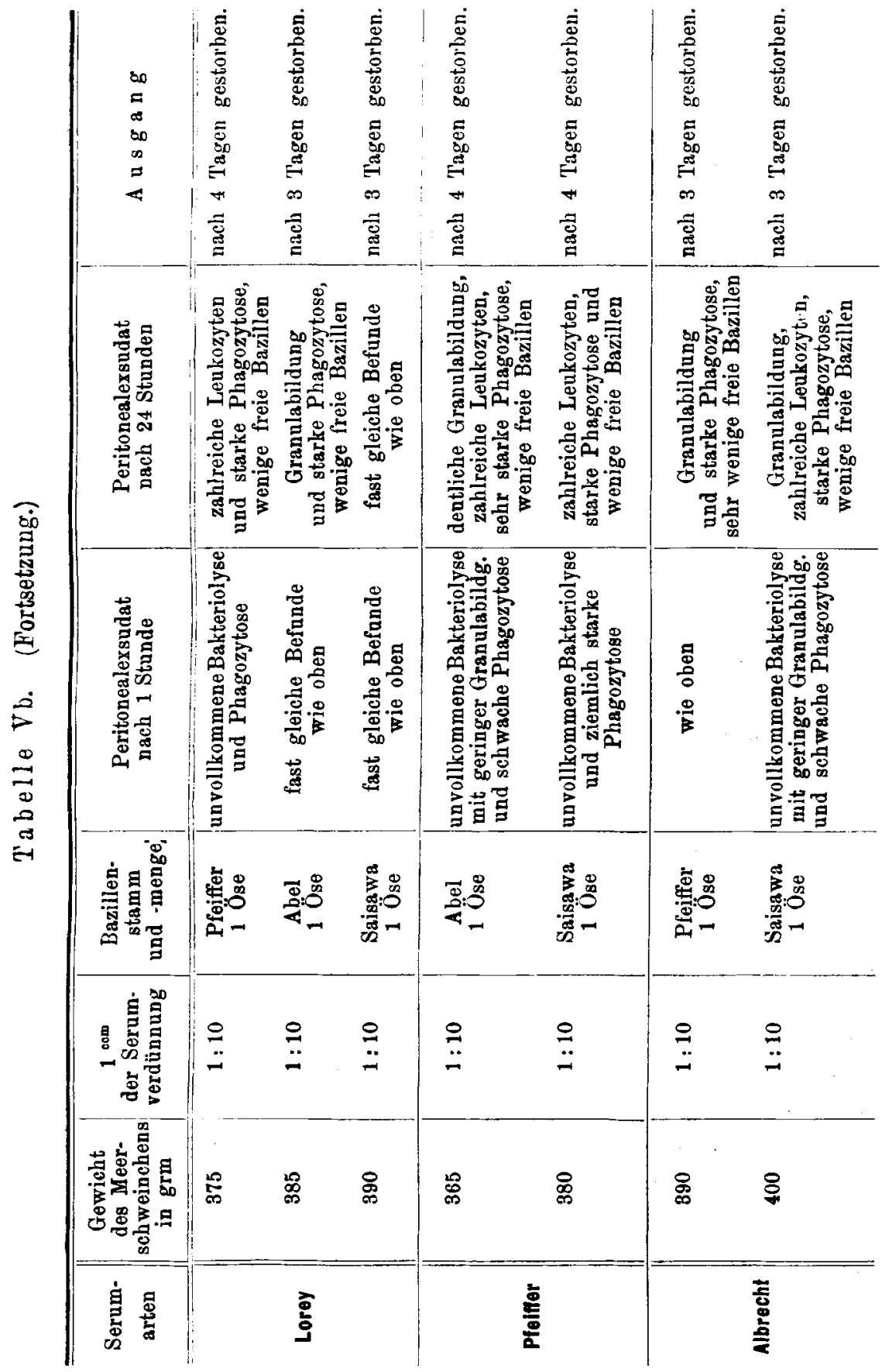


5. Verhalten aktiv immunisierter Meerschweinchen gegen sublutane Einspritzung ron lebenden Bazillen.

Da die bisherigen Versuche, einen einwandfreien Beweis für die Identität oder Nicht-Identität der fünf Bazillenstämme zu erbringen, befriedigende Resultate nicht erbracht hatten, zog ich zur endgültigen Entscheidung der Frage noch den Versuch heran, zu prüfen, ob ein mit einem der Stämme aktiv immunisiertes Meerschweinchen gegen die Infektion mit einem der anderen Stämme wirksam geschützt ist. Hierzu habe ich zunächst mit jedem Stamm, und zwar mittels sublutaner Injektion bei $58^{\circ} \mathrm{C}$ abgetöteter Kultur 8 bis 10 Meerschweinchen immunisiert. Die verabreichte Dosis steigerte ich in 6- bis 7 tägigen Intervallen von $1 / 2$ Ose bis 4 Ósen Kultur, indem ich bei jeder Injektion die Dosis verdoppelte. Mehrere Tiere starben während der Immunisierung an Marasmus oder infolge der Eiterungen, welche nach den Einspritzungen oft eintraten. Die Sektion dieser Tiere ergab keine sichtbaren pathologischen Veränderungen in den inneren Organen. Den am Leben gebliebenen immunisierten Meerschweinchen habe ich 10 Tage nach der letzten immunisatorischen Impfung je 2 Ǒsen lebender Bazillen von den rerschiedenen Stämmen subkutan eingespritzt. Zur Kontrolle erhielten nicht vorbehandelte Meerschweinchen die gleichen Dosen lebender Bazillen. Die Resultate zeigt Tabelle VI.

Fs blieben also alle immunisierten Tiere trotz der nachfolgenden Infektion mit einer sicher tödlichen Dosis lebender Kultur am Leben. Dagegen gingen alle Kontrolltiere in der üblichen Zeit zugrunde und alle wiesen die typischen anatomischen Veränderungen mit ausgedehnter Knötchenbildung auf. Bei den immunisierten Tieren trat nach der Einspritzung von lebenden Bazillen nur teilweise eine lokale Vereiterung ein, welche aber in etwa 10 Tagen durch AbstoBung der nekrotischen Gewebe, b2w. durch Entleerung des Eiters von selbst heilte. Aus dem Eiter konnte ich wieder die eingespritzten Bazillen züchten, woraus hervorgeht, daB keine lokale Immunität des subkutanen Gewebes stand. Nach 4 Wochen habe ich die Tiere getötet. Die Sektion (vgl. Tabelle VI) ergab nur bei den mit dem Abelschen Stamm immunisierten Meerschweinchen nach Einspritzung des Abelschen und meines Stammes und ferner bei dem mit dem Albrechtschen Stamme immunisierten Tiere nach Infektion mit Pfeifferschen Bazillen in Lunge und Leber einige kleine Knötchen, in denen aber weder mikroskopisch noch kulturell Bazillen nachgewiesen werden konnten. In der Milz und in den Mesenterialdrüsen, die meist geschwollen waren, fanden sich bei keinem der Tiere Knötchen. 
Tabelle VI.

\begin{tabular}{|c|c|c|c|c|}
\hline 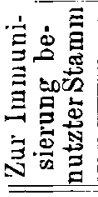 & 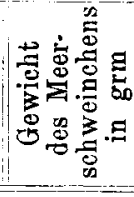 & \begin{tabular}{|c|} 
Das Tier \\
erhielt \\
zwei Ösen \\
lebender \\
Kultur \\
von Stamm
\end{tabular} & $R$ es u l tat & $\begin{array}{l}\text { Nach } 4 \text { Wochen getötet. } \\
\text { Befund nach der Sektion }\end{array}$ \\
\hline \multirow{5}{*}{$\frac{5}{ \pm}$} & 380 & Pfeiffer & $\begin{array}{l}\text { geimpfte Stelle vereitert, } \\
\text { später abgestoßen und } \\
\text { geheilt, bleibt am Leben }\end{array}$ & $\begin{array}{l}\text { Milz etwas vergröBert. } \\
\text { Mesenterialdr. geschwollen. } \\
\text { Nirgends in den Brust- und } \\
\text { Bauchorganen Knötchen- } \\
\text { bildung }\end{array}$ \\
\hline & 350 & Saisawa & $\begin{array}{c}\text { geimpfte Stelle wenig ver- } \\
\text { eitert. Tier lebt }\end{array}$ & $\begin{array}{l}\text { Milz grob. Einige Mesen- } \\
\text { terialdrüsen vergrößert. }\end{array}$ \\
\hline & 345 & Abel & $\begin{array}{l}\text { geimpfte Stelle vereitert, } \\
\text { später abgestoBen. Tier lebt }\end{array}$ & Milz fast normal. \\
\hline & 300 & Lorey & $\begin{array}{c}\text { geimpfte Stelle schwielig } \\
\text { verhärtet. Tier bleibt } \\
\text { am Leben }\end{array}$ & $\begin{array}{l}\text { Milz und Leber vergröBert } \\
\text { (dunkelrot). Mesenterial- } \\
\text { drüsen geschwollen. }\end{array}$ \\
\hline & 340 & Albrecht & $\begin{array}{l}\text { geimpfte Stelle induriert. } \\
\text { Tier bleibt am Leben }\end{array}$ & $\begin{array}{l}\text { Milz und Mesenterial- } \\
\text { drüsen vergröBert. }\end{array}$ \\
\hline \multirow{5}{*}{$\begin{array}{l}- \\
0 \\
a\end{array}$} & 355 & Abel & $\begin{array}{l}\text { geimpfte Stelle vereitert, } \\
\text { später narbig geheilt. } \\
\text { Tier bleibt am Leben }\end{array}$ & $\begin{array}{l}\text { Milz stark vergrößert. } \\
\text { In der Leber und Lunge } \\
\text { einige kleine Kuötchen. }\end{array}$ \\
\hline & 370 & Pfeiffer & $\begin{array}{l}\text { geimpfte Stelle vereitert, } \\
\text { später gereinigt. Tier bleibt } \\
\text { am Leben }\end{array}$ & $\begin{array}{l}\text { Milz und Leber vergröBert. } \\
\text { Mesenterialdr. geschwollen. }\end{array}$ \\
\hline & 350 & Saisawa & $\begin{array}{l}\text { geimpfte Stelle narbig, } \\
\text { induriert. } \\
\text { Tier bleibt am Leben }\end{array}$ & $\begin{array}{l}\text { Milz stark vergröBert. In der } \\
\text { Leber nnd Lunge einige } \\
\text { kleine Knötchen. Mesen- } \\
\text { terialdrüsen geschwollen. }\end{array}$ \\
\hline & 340 & Lorey & $\begin{array}{l}\text { geimpfte Stelle wenig ver- } \\
\text { eitert. Tier bleibt am Leben }\end{array}$ & $\begin{array}{c}\text { Milz und Mesenterialdrüsen } \\
\text { vergröBert. }\end{array}$ \\
\hline & 345 & Albrecht & $\begin{array}{c}\text { geimpfte Stelle vereitert, } \\
\text { später abgestoBen. } \\
\text { Tier bleibt am Leben }\end{array}$ & Milz and Leber vergröBert. \\
\hline \multirow{5}{*}{$\begin{array}{l}= \\
= \\
0 \\
2 \\
=\end{array}$} & 360 & Albrecht & $\begin{array}{l}\text { geimpfte Stelle vereitert, } \\
\text { später geheilt. } \\
\text { Tier bleibt am Leben }\end{array}$ & $\begin{array}{l}\text { Milz ziemlich groB, ebenso } \\
\text { Leber vergröBert, einige } \\
\text { Mesenterialdrüs. vergröbert. }\end{array}$ \\
\hline & 320 & Pfeiffer & $\begin{array}{l}\text { geimpfte Stelle wenig ver- } \\
\text { eitert. Tier bleibt am Leben }\end{array}$ & $\begin{array}{l}\text { Milz stark vergrößert. In } \\
\text { der Leber und Lunge einige } \\
\text { kleine Knötch. Mesenterial. } \\
\text { drüsen auch geschwollen. }\end{array}$ \\
\hline & 350 & Saisawa & desgl. & $\begin{array}{l}\text { Milz sehr groB. Mesenterial- } \\
\text { drüsen geschwollen. }\end{array}$ \\
\hline & 340 & Lorey & $\begin{array}{l}\text { geimpfte Stelle induriert. } \\
\text { Tier bleibt am Leben. }\end{array}$ & $\begin{array}{l}\text { Milz und Leber, sowie } \\
\text { Mesenterialdr. vergröBert. }\end{array}$ \\
\hline & 380 & Abel & $\begin{array}{l}\text { geimpfte Stelle vereitert, } \\
\text { später abgestoBen. } \\
\text { Tier bleibt am Leben }\end{array}$ & $\begin{array}{l}\text { Milz und einige Mesenterial- } \\
\text { drüsen vergröbert. }\end{array}$ \\
\hline
\end{tabular}


Tabelle VI. (Fortsetzung.)

\begin{tabular}{|c|c|c|c|c|}
\hline 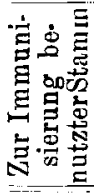 & 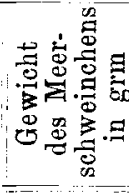 & $\begin{array}{c}\text { Das Tier } \\
\text { erhiëlt } \\
\text { zwei Ösen } \\
\text { lebender } \\
\text { Kultur } \\
\text { von Stamm }\end{array}$ & $R$ es $u l t a t$ & $\begin{array}{l}\text { Nach } 4 \text { Wochen getötet. } \\
\text { Befund nach der Sektion }\end{array}$ \\
\hline \multirow{5}{*}{$\begin{array}{l}\infty \\
3 \\
\infty \\
\infty \\
\pi \\
\infty\end{array}$} & 320 & Saisawa & $\begin{array}{l}\text { geimptte Stelle vereitert, } \\
\text { später abgestoBen. } \\
\text { Tier bleibt am Leben }\end{array}$ & $\begin{array}{c}\text { Milz etwas vergrößert. } \\
\text { Mesenterialdrüsen } \\
\text { geschwollen }\end{array}$ \\
\hline & 380 & Pfeiffer & $\begin{array}{l}\text { geimpfte Stelle induriert. } \\
\text { Tier bleibt am Leben }\end{array}$ & $\begin{array}{l}\text { Milz groB, einige Mesenterial } \\
\text { drüsen vergröBert. }\end{array}$ \\
\hline & 345 & Abel & $\begin{array}{l}\text { geimpfte Stelle induriert. } \\
\text { Tier bleibt am Leben }\end{array}$ & $\begin{array}{l}\text { Milz fast normal, einige } \\
\text { Mesenterialdr. geschwollen. }\end{array}$ \\
\hline & 390 & Lorey & $\begin{array}{l}\text { geimpfte Stelle vereitert, } \\
\text { später abgestoßen. } \\
\text { Tier bleibt am I eben }\end{array}$ & $\begin{array}{c}\text { Milz, Leber und } \\
\text { Mesenterialdrüsen } \\
\text { vergröBert. }\end{array}$ \\
\hline & 330 & Albrecht & $\begin{array}{c}\text { geimpfte Stelle vereitert, } \\
\text { später gereinigt. } \\
\text { Tier bleibt am Leben }\end{array}$ & $\begin{array}{l}\text { Milz sehr groB. Mesenterial- } \\
\text { drüsen auch vergröBert. }\end{array}$ \\
\hline \multirow{5}{*}{$\begin{array}{l}3 \\
0 \\
0 \\
j\end{array}$} & 340 & Lorey & $\begin{array}{l}\text { geimpfte Stelle vereitert, } \\
\text { später geheilt. } \\
\text { Tier bleibt am Leben }\end{array}$ & Milz vergröBert. \\
\hline & 365 & Pfeiffer & $\begin{array}{l}\text { geimpfte Stelle wenig ver- } \\
\text { eitert. Tier bleibt am Leben }\end{array}$ & $\begin{array}{l}\text { Milz ziemlich groß, einige } \\
\text { Mesenterialdrüs. vergrößert. }\end{array}$ \\
\hline & 320 & Saisawa & $\begin{array}{l}\text { geimpfte Stelle narbig ver } \\
\text { bärtet. Tier bleibt am Leben }\end{array}$ & $\begin{array}{l}\text { Milz und Ieber vergröbert, } \\
\text { Mesenterialdr. geschwollen. }\end{array}$ \\
\hline & 380 & Abel & $\begin{array}{l}\text { geimpfte Stelle vereitert, } \\
\text { später geheilt. } \\
\text { Tier bleibt am Leben }\end{array}$ & $\begin{array}{l}\text { Milz sehr groB, Mesenterial- } \\
\text { drüsen vergröBert. }\end{array}$ \\
\hline & 345 & Albrecht & $\begin{array}{c}\text { geimpfte Stelle vereitert, } \\
\text { später abgestoßen. } \\
\text { Tier bleibt am Leben }\end{array}$ & Milz und Leber vergröBert. \\
\hline
\end{tabular}

\begin{tabular}{|c|c|c|c|c|}
\hline & 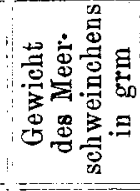 & $\begin{array}{c}\text { Bazillen- } \\
\text { stamm, } \\
\text { subkutan } \\
\text { ein- } \\
\text { gespritzte } \\
\text { Dosis } 1 \text { Ose }\end{array}$ & A u s g a n g & Befund bei der Sektion \\
\hline$=\stackrel{\vec{i}}{\vec{J}}$ & 380 & Pfeiffer & nach 14 Tagen gestorben & typisch \\
\hline$=\stackrel{\vec{n}}{=}$ & 355 & Saisawa & nach 9 Tagen gestorben & $"$ \\
\hline 룔 & 360 & Abel & nach 12 Tagen gestorben & $"$ \\
\hline$=$ & 365 & Lorey & nach 10 Tagen gestorben & , \\
\hline$\times$. & 350 & Albrecht & nach 11 Tagen gestorben & $"$ \\
\hline
\end{tabular}


Diese Tatsache scheint mir sehr bemerkenswert zu sein. Da sich in der Milz gar keine Knötchen fanden, und in den Knötchen der Lunge und Leber keine Bazillen hachzuweisen waren, so läBt sich vermuten, daB die Bazillen bereits abgetötet waren, so daB die Tiere sich auf dem Wege zur Besserung befanden und sicher mit dem Leben davongekommen wären. Die Ergebnisse dieser Untersuchungen beweisen also, daB die aktive Immunisierung mit einem der Stämme ein wirksamer Schutz ist gegen die Infektion mit allen anderen von mir untersuchten Stämme.

Fasse ich die erhaltenen Resultate zusammen, so komme ich zu folgendem Schluß: Die geprüften fünf Bazillenstämme zeigen morphologisch und kulturell keine wesentlichen Unterschiede. Auch ihr Verhalten bezüglich der Säure- und Alkalibildung in den verschiedenen Kohlehydratlösungen ist stets das gleiche. Für Nagetiere - Meerschweinchen, Kaninchen und Mäuse - sind sie stark pathogen; die Tiere erliegen fast ohne Ausnahme der Infektion. Ihre inneren Organe zeigen bei nicht akutem Verlauf charakteristische anatomische Veränderungen, vorzugsweise bestehend in hochgradiger Schwellung und Hyperämie von Milz, Leber und Mesenterialdrüsen, sowie starker Knötchenbildung in fast allen inneren Organen. Diese Beobachtungen stimmen vollständig mit den Beschreibungen überein, die A. Pfeiffer und Preisz über ihren Pseudotuberkulosebacillus der Nagetiere geben. Die Serumreaktionen, und zwar die Agglutinations-, Präzipitations- und Komplementbindungsreaktion, sowie der Pfeiffersche Versuch ergeben sehr unsichere Resultate, so daß sie zur Identifizierung der verschiedenen Stämme dieser Bakterienart wenig geeignet erscheinen. Nur mit dem von dem Abelschen Bacillus stammenden Serum erhielt ich einigermaßen eindeutige Resultate. Dagegen sprach die Prüfung des durch aktive Immunisierung erzielten Impfschutzes gegen die nachfolgende Infektion mit lebender Bazillenkultur einwandfrei für die Identität der fünf von mir geprüften Stämme.

In der Praxis wird also bei der Diagnostik der Pseudotuberkulosebazillen der Nagetiere nicht die Prüfung der verdächtigen Kulturen mittels der gebräuchlichen, im Reagensglase vorzunehmenden Immunitätsreaktionen ausschlaggebend sein, sondern neben ihrem morphologischen und kulturellen Verhalten, sowie im besonderen auch den pathologisch-anatomischen Veränderungen beim infizierten Tiere vor allem die Prüfung des durch die aktive Immunisierung zu erzielenden Impfschutzes gegenüber einer vollvirulenten sicheren Pseudotuberkulosekultur. 
420 K. Saisawa: Uber den Bacillus der Pseddotdberkolose.

Die von Lorey geäuBerte Vermutung, daß der von ihm beschriebene Bacillus der Erreger der Pseudotuberkulose ist, haben meine Untersuchungen durchaus bestätigt.

\section{Literatur.}

Vgl. meine vorstehende Arbeit; anBerdem:

Galli-Valerio, Centralblatt für Bakteriologie. 1903. Bd. XXXlII.

Zlatogor off, Ebenda. 1904. Bd. XXXVII. 